\title{
INFLUÊNCIA DOS MÉTODOS DE SECAGEM DE AMOSTRAS DE FOLHAS DE CAPIM BRAQUIÁRIA, CANA-DE-AÇÚCAR E GOIABEIRA NOS TEORES DE MACRONUTRIENTES
}

\author{
André Luiz Pereira da Silva ${ }^{1}$; Renato de Mello Prado ${ }^{2}$; Gilson Silvério da Silva ${ }^{1}$; Matheus Saraiva Bianco; \\ Márcio Alexandre Pancelli ${ }^{1}$ \\ (1) Pós-graduandos em Agronomia, Faculdade de Ciências Agrárias e Veterinárias, UNESP Campus Jaboticabal. \\ (2) Professor Doutor do Departamento de Solos e Adubos da Faculdade de Ciências Agrárias e Veterinárias, UNESP Campus \\ Jaboticabal. Bolsista PQ do CNPq.
}

\section{RESUMO}

A secagem de amostras de folhas em forno microondas pode ser promissora se não afetar os teores dos nutrientes nas amostras, comparada ao método convencional em estufa. Assim, o presente trabalho objetivou avaliar os efeitos da secagem de amostras de folhas das culturas de capim braquiária, cana-deaçúcar e goiabeira, utilizando o forno microondas e a estufa sobre os teores foliares de macronutrientes. Para isto, realizou-se um estudo em condições de laboratório, na UNESP- Campus de Jaboticabal-SP. Os tratamentos foram constituídos por um fatorial $3 \times 2$, sendo três espécies vegetais, (capim braquiária, canade-açúcar e goiabeira) e dois métodos de secagem (forno microondas e estufa de circulação forçada de ar), dispostos em delineamento inteiramente causalizado com seis repetições. Nas amostras das folhas foi realizada análise química determinando-se os teores foliares dos macronutrientes. Os métodos de secagem não afetaram os teores foliares de nitrogênio, fósforo, potássio e magnésio das culturas de capim braquiária, goiaba e cana-de-açúcar. Para os teores foliares de enxofre, o forno microondas apresentou maiores valores destes nutrientes para as três culturas. Os teores foliares de Ca foram maiores na secagem da goiabeira em forno microondas.

Palavras-chave: Brachiaria decumbens; Saccharum officinarum; Psidium guajava; análise química de plantas.

\section{EVALUATION OF DRYING METHODS FOR DETERMINATION OF MACRONUTRIENT CONTENTS IN LEAF SAMPLES OF BRACHIARIA GRASS, SUGARCANE AND GUAVA}

\begin{abstract}
Drying leaf samples in microwave oven may be a promising method if it does not affect the levels of nutrients in the samples, compared to conventional drying oven procedure. This study aimed to evaluate the effects of drying leaf samples using microwave oven on the foliar concentrations of macronutrients of brachiaria grass, cane sugar and guava. For this, a study was carried out in a 3×2 factorial arrangement, with three plant species and two drying methods, microwave oven and forced-air circulation oven, arranged in a randomized block design with six replications. Leaf samples were analyzed for determining their macronutrient levels. The drying methods did not affect foliar concentrations of nitrogen, phosphorus, potassium and magnesium in all three species studied. However, leaves dried in microwave oven showed higher values of sulfur in all three species. Also, Ca content was higher in guava leaves dried in microwave oven.
\end{abstract}

Keywords: Brachiaria decumbens; Saccharum officinarum; Psidium guajava; chemical analysis of plants. 


\section{INTRODUÇÃO}

A análise de tecido vegetal é importante ferramenta na avaliação do estado nutricional das plantas e da fertilidade do solo, pois com a interpretação desses resultados tem-se a possibilidade de efetuar ajustes na adubação, visando atender as exigências nutricionais das culturas e proporcionar alta produção e retorno econômico da atividade agrícola.

De acordo à metodologia de análise química de folhas, deve-se seguir corretamente 0 preparo da amostra, como lavagem, secagem e armazenamento, para obter o material vegetal adequado que será encaminhado para análise. Após lavagem do material vegetal, é preciso realizar a sua secagem, para evitar a degradação e alterações químicas dos tecidos durante 0 armazenamento, e também para facilitar a moagem das amostras além de ser necessário para a determinação da matéria seca (PRADO, 2008).

Segundo Pastorini, Bacarin e Abreu (2002) e Marur e Sodek (1995), existem dois métodos que são usados para secagem de tecidos vegetais, a secagem em estufa de ar forçado e a liofilização. A liofilização mantém a maioria das propriedades bioquímicas do tecido vegetal, mas tem a desvantagem de ser um procedimento lento e que requer equipamento dispendioso. A secagem em estufa é simples, amplamente utilizado nos laboratórios de nutrição de plantas, mas tem a desvantagem de que mudanças bioquímicas podem ocorrer no material e ter sua composição alterada. Marur (1995) acrescenta ainda a possibilidade de secagem por meio de forno microondas, com vantagens quanto a maior velocidade na secagem do material vegetal, acessibilidade $e$, principalmente, a redução das transformações químicas durante o processo de aquecimento, mas com possíveis perdas significativas de carboidratos durante 0 processo de secagem, através da respiração, assim como algumas substâncias voláteis, dependendo do tempo de secagem do material.

Neste sentido, existem algumas pesquisas, indicando o uso do forno microondas na rotina de laboratórios para a secagem de diversos materiais como solo e tecido vegetal (SOUZA; NOGUEIRA; RASSINI, 2002) e especialmente na determinação da matéria seca em diversos materiais vegetais como milho (VALENTINI; CASTRO; ALMEIDA, 1998; SCHENA, 2007) e em forrageiras como capim elefante (FIGUEIREDO, 2004).

Diante disso, existe a possibilidade de uso deste método de secagem com uso do forno microondas para a secagem de folhas, que pode secar o material rapidamente em 22 minutos em média, comparado com método de secagem convencional em estufa, que pode atingir de 48 a 72 horas dependendo do tipo de material vegetal, teor de água e da temperatura (LACERDA et al., 2009), agilizando a rotina laboratorial, reduzindo 0 tempo para emissão dos laudos e para as tomadas de decisões no que se refere às adubações corretivas, podendo ser um diferencial em termos de proporcionar altas produtividades das culturas.

No entanto, para usar esse método de secagem em forno de microondas é importante avaliar se isso poderia afetar os teores foliares dos nutrientes das plantas e consequentemente a respectiva interpretação dos resultados da análise foliar. Na literatura existem poucas informações sobre os efeitos da secagem em forno microondas no teor foliar de nutrientes das plantas cultivadas, tendo estudos restritos em frutíferas (MARCANTE et al., 2010) e em alface (BORGES et al., 2011).

Diante deste contexto, 0 presente trabalho objetivou avaliar os efeitos da utilização de forno microondas e estufa sobre a secagem de amostras de folhas de capim braquiária, cana-de- 
açúcar e goiabeira, em relação aos teores foliares de macronutrientes.

\section{MATERIAL E MÉTODOS}

O presente trabalho foi desenvolvido em condições de laboratório, utilizando amostras de folhas das culturas de capim-braquiária, cana-deaçúcar e de goiabeira cultivadas na Fazenda Experimental da UNESP - Campus de Jaboticabal.

Os tratamentos foram constituídos por um fatorial $3 \times 2$, sendo três espécies vegetais (capim brachiária, cana-de-açúcar e goiabeira) e dois métodos de secagem (forno microondas e estufa de aeração forçada de ar), dispostos em delineamento inteiramente causalizado com seis repetições. Para isso, realizou-se inicialmente a amostragem das folhas (02-09-2009), considerando para a cana-de-açúcar, a folha +1 com colarinho visível (TVD), retirando os $20 \mathrm{~cm}$ centrais, excluindo a nervura central (RAIJ, 1997); para o capim brachiária coletaram-se as folhas recém-maduras, retirando a terceira folha completamente expandida (MARTINEZ; CARVALHO; SOUZA, 1999) e para a goiabeira foram coletadas $O$ terceiro par de folhas totalmente desenvolvidas (QUAGGIO; RAIJ; PIZA JUNIOR, 1997), tendo sido coletada 15 amostras de folhas para compor a amostra composta.

Após a coleta das amostras de folhas, as mesmas foram identificadas e enviadas ao laboratório de Nutrição de Plantas da UNESP Campus Jaboticabal, e no mesmo dia realizou os procedimentos de descontaminação do material através da lavagem do material com a seguinte seqüência: água corrente destilada; solução detergente $(0,1 \%)$; solução de ácido clorídrico $(0,3 \%)$; água deionizada e secagem, conforme descritos por Prado (2008).

As folhas foram picadas em pedaços com cerca de $20 \mathrm{~mm}$ e acondicionadas em sacos de papel identificados para posterior aplicação dos tratamentos. Assim, os materiais vegetais foram submetidos à secagem, utilizando-se: a) o método convencional a partir da estufa de circulação forçada de ar com temperatura de 65 a $70^{\circ} \mathrm{C}$, onde o material permaneceu por 72 horas, realizando a medição da massa a cada 24 horas, até atingir a massa constante (PRADO, 2008); e b) o forno microondas indicado por Lacerda; Freitas e Silva (2009), onde cada amostra foi submetida a 3 ciclos de 5 minutos, 1 ciclo de 3 minutos, 1 ciclo de 2 minutos e 1 ciclo de 1 minuto (até atingir peso constante). A cada ciclo no forno microondas foi realizada a medição da massa da matéria seca logo após o resfriamento das amostras. $O$ forno de microondas (Panasonic) apresentava as seguintes características: carga máxima de $5 \mathrm{~kg}$, capacidade de $35 \mathrm{~L}$, tensão de alimentação de $220 \mathrm{~V}$, corrente de $13 \mathrm{~A}$, frequência de $60 \mathrm{~Hz}$ (rede), potência útil de $1100 \mathrm{~W}$ (máxima), frequência de $2450 \mathrm{MHz}$ (operação), consumo de 1,6 kW/hora, velocidade do prato giratório de $3 \mathrm{rpm} \mathrm{e}$ dimensões externas de $306 \times 555 \times 428 \mathrm{~mm}$. A cada ciclo regular de utilização do forno microondas, o material vegetal seco foi desprendido do recipiente com uma espátula, a fim de evitar a fixação na sua superfície e também com o intuito de evitar a combustão. No interior do forno microondas foi colocado um béquer com $150 \mathrm{~mL}$ de água com a finalidade de umedecer o ambiente e evitar a combustão das amostras e danos no aparelho (UNDERSANDER; MERTENS; THIEX, 1993). A água do béquer foi trocada a cada nova seqüência para evitar que entrasse em ebulição e derramasse água nas amostras, alterando sua umidade e aumentando o tempo de secagem.

Após a secagem do material vegetal, realizou-se a moagem das amostras em moinho com câmara de aço inoxidável tipo Willey equipado com peneira de 40 mesh visando a obtenção de material fino e homogêneo para em 
seguida realizar a análise química determinandose os teores dos macronutrientes, conforme indicações de Bataglia et al. (1983).

Os dados foram submetidos à análise de variância e utilizou-se como teste de comparação de médias, o Tukey a 5\% de probabilidade, através do software AgroEstat (BARBOSA; MALDONADO JÚNIOR, 2011).

\section{RESULTADOS E DISCUSSÃO}

Pelos resultados obtidos houve efeito apenas para o fator culturas sobre os teores foliares de todos os macronutrientes, exceto para o cálcio onde houve interação entre os fatores cultura e método de secagem (Tabela 1).

Observou-se que os teores foliares de $\mathrm{N}$, $\mathrm{P}, \mathrm{K}, \mathrm{Mg}$ das culturas avaliadas não foram influenciados pelos métodos de secagem do tecido vegetal (Tabela 1). Assim, para estes macronutrientes os resultados indicam a semelhança dos dois métodos de secagem e, portanto não influenciaria no futuro diagnóstico destes importantes nutrientes nas culturas do capim braquiária, da goiabeira e da cana-deaçúcar. Resultados semelhantes foram obtidos por outros autores que indicaram que não houve diferença entre os dois métodos de secagem de folhas para os teores de macronutrientes em alface (BORGES et al., 2011) e em abacate, maracujá e pêssego, exceto esta última cultura para Ca (MARCANTE et al., 2010).

Observou-se ainda que houve diferença entre os métodos de secagem para os teores foliares de cálcio e enxofre, ocorrendo interação apenas para o primeiro nutriente (Tabela 1). Assim, nota-se que os teores de cálcio são influenciados pelos métodos de secagem e conforme o tipo de folha avaliado.

Tabela 1 - Teor foliar de macronutrientes nas espécies de capim braquiária, goiabeira e cana-de-açúcar em função dos métodos de secagem.

\begin{tabular}{|c|c|c|c|c|c|c|}
\hline Fonte de variação & $\mathrm{N}$ & $\mathrm{P}$ & $\mathrm{K}$ & $\mathrm{Ca}$ & $\mathrm{Mg}$ & $\mathrm{S}$ \\
\hline \multirow{2}{*}{\multicolumn{6}{|c|}{ Culturas (C) }} & \\
\hline Braquiária & 2110 & & & & & \\
\hline & & & & 4,10 & & \\
\hline Goiabeira & 16,15 & 1,62 & 14,19 & 11,65 & 2,94 & 2,31 \\
\hline Cana-de-açúcar & 20,55 & 2,21 & 13,85 & 2,79 & 1,15 & 2,39 \\
\hline Teste F (C) & $10,49^{* *}$ & $20,20^{* *}$ & $82,14^{* *}$ & $255,95^{\star *}$ & $73,36^{* *}$ & $10,18^{\star *}$ \\
\hline \multicolumn{7}{|l|}{$\begin{array}{l}\text { Métodos de } \\
\text { secagem (M) }\end{array}$} \\
\hline Microondas & 19,30 & 1,87 & 17,31 & 6,67 & 2,20 & 2,40 \\
\hline Estufa & 19,23 & 1,94 & 17,88 & 5,37 & 2,05 & 2,17 \\
\hline Teste F (M) & $0,01^{\text {ns }}$ & $0,71^{\text {ns }}$ & $0,05^{\mathrm{ns}}$ & $16,58^{* *}$ & $1,45^{\text {ns }}$ & $20,90^{* *}$ \\
\hline Teste F (CxM) & $1,16^{\text {ns }}$ & $2,28^{\text {ns }}$ & $0,93^{\text {ns }}$ & $4,94^{*}$ & $0.04^{\mathrm{ns}}$ & $2,16^{\text {ns }}$ \\
\hline C.V.(\%) & 15,0 & 11,9 & 13,4 & 11,1 & 17,0 & 5,7 \\
\hline
\end{tabular}

A interação ocorreu pelo fato de que o teor de Ca diferiu apenas na cultura da goiabeira, onde houve maior teor deste nutriente com emprego da secagem pelo forno microondas, ao passo que para as demais culturas os métodos de secagem foram semelhantes (Tabela 2).
Apesar de existir uma diferença no teor de $\mathrm{Ca}$ para a cultura da goiabeira entre os métodos de secagem, ou seja, $12 \mathrm{~g} \mathrm{~kg}^{-1}$ e $10 \mathrm{~g} \mathrm{~kg}^{-1}$ de Ca nas folhas quando se usa o forno microondas e a estufa, respectivamente, se esses valores forem comparados com a faixa adequada sugerida por 
Quaggio et al. (1997), que é de 9 a $15 \mathrm{~g} \mathrm{~kg}^{-1}$, ambas as amostras estariam na faixa adequada da cultura. Portanto, essa diferença entre os dois métodos de secagem de folhas de goiabeira para - Ca não iria alterar diagnóstico da cultura. Entretanto, para o S observou-se que o método da secagem pelo forno microondas apresentou teor mais elevado $\left(2,4 \mathrm{~g} \mathrm{~kg}^{-1}\right)$ em relação à secagem pela estufa (2,2 $\left.\mathrm{g} \quad \mathrm{kg}^{-1}\right)$, independentemente da folha da cultura analisada.

Nota-se ainda, na comparação entre as três culturas dentro de cada método de secagem, que o teor foliar de cálcio foi sempre maior para a goiabeira e menor para a cana-de-açúcar nos dois métodos de secagem (Tabela 2), o que indica que a folha da goiabeira poderia ter maior demanda de $\mathrm{Ca}$, avaliada tanto em amostras secas em estufa como em forno de microondas.

Tabela 2 - Desdobramento do teor foliar de cálcio em capim- braquiáriaria, goiabeira e cana-deaçúcar em função dos métodos de secagem.

\begin{tabular}{lccc}
\hline Culturas & Métodos de secagem & $\begin{array}{c}\text { DMS } \\
(5 \%)\end{array}$ \\
\hline \multicolumn{4}{c}{$\begin{array}{c}\text { Forno } \\
\text { microondas }\end{array}$} \\
\hline \multicolumn{4}{c}{$\mathrm{g} \mathrm{kg}^{-1}$} \\
Braquiária & $4,42 \mathrm{bA}$ & $3,95 \mathrm{bA}$ & 0,81 \\
Goiabeira & $12,63 \mathrm{aA}$ & $10,67 \mathrm{aB}$ & 0,81 \\
Cana-de- & $2,98 \mathrm{cA}$ & $2,60 \mathrm{cA}$ & 0,81 \\
açúcar & \multicolumn{4}{c}{0,98} \\
\hline DMS (5\%) & 0,98 \\
*Médias seguidas pela mesma letra maiúscula na horizontal e \\
minúscula na vertical, não diferem entre si a $5 \%$ pelo teste de \\
Tukey.
\end{tabular}

Diante da pouca informação na literatura sobre métodos de secagem de folhas é importante ressaltar necessidade de mais estudos comparando esses métodos de secagem de amostras em outras culturas, pois os tecidos vegetais apresentam composição química e quantidades de compostos orgânicos estruturais como lignina e celulose distintas, os quais poderiam interferir na secagem do material.

\section{CONCLUSÃO}

Os métodos de secagem não afetaram os teores foliares de nitrogênio, fósforo, potássio e magnésio das culturas de capim braquiária, goiaba e cana-de-açúcar. A secagem em forno microondas resultou em maior teor foliar de enxofre para as três culturas. Para os teores foliares de $\mathrm{Ca}$, a utilização de forno microondas resultou em maiores teores foliares na cultura da goiabeira.

\section{REFERÊNCIAS}

BATAGLIA, O.; C. FURLANI, A. M. C.; TEIXEIRA, J. P. F.; FURLANI, P. R.; GALLO, J. R. Métodos

de análise química de plantas. Campinas: Instituto Agronômico,1983. 48 p. (Boletim Técnico, 78).

BARBOSA, J. C.; MALDONADO JR., W.

AgroEstat - Sistema de Análises Estatísticas de Ensaios Agronômicos. Jaboticabal: Faculdade de Ciências Agrárias e Veterinárias, UNESP, 2011.

BORGES, B. M. M. N.; MODESTO, V. C.; PRADO, R. M.; SILVA, E. S.; BRAOS, B. B. Métodos de determinação da matéria seca e dos teores de macronutrientes em folhas de alface.

Revista Trópica, v. 5, p. 12-16, 2011.

FIGUEIREDO, M. P.; FIGUEIREDO, M. P. de; SOUSA, S. A.; MOREIRA, G. R.; SOUSA, L. F.; FERREIRA, J. Q. Determinação do teor de matéria seca do capim elefante (Penninsetum purpureum Schum), em três estádios de maturidade fisiológica, pelo forno de microondas.

Magistra, v. 16, n. 2, p. 113-119, 2004.

LACERDA, M. J. R.; FREITAS, K. R.; SILVA, J. W. Determinação da matéria seca de forrageiras pelos métodos de microondas e convencional.

Bioscience Journal, v. 25, n. 3, p. 185-190, 2009.

MARCANTE, N. C.; PRADO, R. M.; SILVA, M. A. C.; ROSSET, J. S.; ECCO, M.; SAVAN, P. A. L. 
Determinação da matéria seca e teores de macronutrientes em folhas de frutíferas usando diferentes métodos de secagem. Ciência Rural, v. 40, p. $2398-2401,2010$.

http://dx.doi.org/10.1590/S0103-

84782010001100025 .

MARTINEZ, H. E. P.; CARVALHO, J. G.; SOUZA, R. B. Diagnose foliar. In: RIBEIRO, A. C.; GUIMARÃES, P. T. G.; ALVAREZ, V. H.

Recomendações para o uso de corretivos e fertilizantes em Minas Gerais - $5^{\text {a }}$

Aproximação. Viçosa: CFSMG, 1999. p. 141168.

MARUR, C. J.; SODEK, L. Microwave drying of plant material for biochemical analysis. Revista

Brasileira de Fisiologia Vegetal, v. 1, n. 7, p. 111-114, 1995.

PASTORINI, L. H.; BACARIN, M. A.; ABREU, C. M. Secagem de material vegetal em forno de microondas para determinação de matéria seca e análises químicas. Ciência e Agrotecnologia, v. 26, n. 6, p. 1252-1258, 2002.

PRADO, R. M. Nutrição de plantas. São Paulo: UNESP, 2008. 407 p.

QUAGGIO, J. A.; RAIJ, B. van.; PIZA JÚNIOR, C.

T. Frutíferas. In: RAIJ, B.van.; CANTARELLA, H.; QUAGGIO, J. A.; FURLANI, A. M. C.

Recomendações de adubação e calagem para o Estado de São Paulo. 2.ed. Campinas: Instituto Agronomia, 1997. p. 121-125. (Boletim Técnico, 100).

RAIJ, B. van; CANTARELA, H. Outras culturas industriais. In: RAIJ, B. van; CANTARELLA, H.; QUAGGIO, J. A.; FURLANI, A. M. C.

Recomendação de adubação e calagem para o Estado de São Paulo. 2.ed. Campinas: IAC, 1997. p. 233-236. (Boletim Técnico, 100).

SCHENA, T. E.; GARBUIO, P. W.; SOUZA, N. M.; DELALIBERA, H. C.; LEITÃO, K.; WEIRICH NETO, P. H. Determinação da matéria seca de plantas de milho (Zea mays L.) destinadas à produção de silagem. In: ENCONTRO DE ENGENHARIA E TECNOLOGIA DOS CAMPOS GERAIS, 3., 2007, Ponta Grossa. Anais: Inovação, Desenvolvimento e Sustentabilidade. Ponta Grossa: Editora UTFPR. 2007.

SOUZA, G. B. de; NOGUEIRA, A. R. A.; RASSINI, J. B. Determinação de matéria seca e umidade em solos e plantas com forno microondas doméstico. São Carlos: Embrapa Pecuária Sudeste, 2002. (Embrapa Pecuária Sudeste, Circular Técnica, 33).

UNDERSANDER, D.; MERTENS, D. R.; THIEX, N. Forage analyses procedures. Omaha: National Forage Testing Association, 1993. 53 p. VALENTINI, S. R. T.; CASTRO, M. F. P. M.; ALMEIDA, F. H. Determinação do teor de umidade de milho utilizando aparelho de microondas. Ciência e Tecnologia de Alimentos, v. 18, n. 2, p. 237-240, 1998. http://dx.doi.org/10.1590/S010120611998000200017 